\title{
Low-temperature synthesis of biomorphic cellular SiC ceramics from wood by using a Na flux
}

\author{
Hisanori YAMANE, Fumihiro KAWAMURA and Takahiro YAMADA \\ Institute of Multidisciplinary Research for Advanced Materials, Tohoku University, 2-1-1, Katahira, Aoba-ku, Sendai 980-8577
}

\begin{abstract}
Wood from balsa and Japanese cypress was transformed into carbonaceous preforms by pyrolysis and subsequently converted into cellular SiC ceramics by heating with $\mathrm{Na}$ and $\mathrm{Si}$ at $973 \mathrm{~K}$ for $86.4 \mathrm{ks}$. X-ray diffraction showed the structure of the formed $\mathrm{SiC}$ to be cubic $\beta$-type. Cellular structures similar to those of the preforms were observed for the resulting porous $\mathrm{SiC}$ ceramics by scanning electron microscopy.
\end{abstract}

Key-words: SiC, Cellular ceramics, Biomorphic materials, Low temperature synthesis, Na flux

[Received September 30, 2007; Accepted November 15, 2007] @2008 The Ceramic Society of Japan

1. Introduction

Porous silicon carbide $(\mathrm{SiC})$ ceramics can be used for a variety of applications including high-temperature resistant exhaust gas filters, molten metal filters, catalyst support and carriers, and lightweight components of machines. ${ }^{1)-3)}$ Besides these applications, they have also been studied as bio-inert and corrosion-resistant immobilization supports for living cells, microbes, or enzymes, and as light weight implant materials for bone substitutions. ${ }^{2)-4)}$

Many processing methods to obtain porous ceramics have been invesitated. ${ }^{5), 6)}$ One of the representative methods for the synthesis of cellular ceramics utilizes natural templates of wood which has an intricate anatomy. Pyrolysis of the wood is carried out in an inert atmosphere to yield a porous carbon template. This template can then be converted into a silicon carbide cellular ceramic by various methods, such as infiltration and reaction with liquid $\mathrm{Si}^{4}{ }^{4,7), 8)} \mathrm{Si}$ containing vapors, ${ }^{9}{ }^{9}$ and infiltration and carbothermal reduction of a sol containing colloidal silica. ${ }^{10)-14)}$ Biomorphic $\mathrm{SiC}$ has also been produced directly from raw wood impregnated with sodium silicate. ${ }^{15)}$ However, high-temperature conditions above 1573-1973 K are necessary for these processes and the crystallization of $\mathrm{SiC}$.

Recently, we found that $\beta$-type cubic $\mathrm{SiC}$ nanopowder could be prepared by the $\mathrm{Na}$ flux method at $900-1000 \mathrm{~K} .{ }^{16}$ ) In that study, a mixture of $\mathrm{Si}$ and fullerene powders was impregnated with a Na melt. When a pellet of a Si and fullerene powder mixture or a $\mathrm{Si}$ and amorphous carbon (carbon black) powder mixture was set in $\mathrm{Na}$ vapor under an $\mathrm{Ar}$ atmosphere at $1000 \mathrm{~K}$, a porous $\mathrm{SiC}$ ceramic pellet having the same shape as the pellet of the original powder mixture was obtained. ${ }^{17)}$ In the present study, we used carbonized wood as a carbon source and a natural template with a cellular structure, and synthesized biomorphic $\mathrm{SiC}$ ceramics at $973 \mathrm{~K}$.

\section{Experimental}

Balsa $(\varphi 10 \mathrm{~mm} \times 40 \mathrm{~mm})$ and Japanese cypress $(10 \times 10 \times$ $30 \mathrm{~mm}$ ) were dried at $353 \mathrm{~K}$ for $14.4 \mathrm{ks}$ in air. Pyrolysis was performed by heating at $823 \mathrm{~K}$ for $21.6 \mathrm{ks}$ under a reduced pressure of $1.3 \times 10^{4} \mathrm{~Pa}$. The following materials were placed in a boron nitride crucible (Showa Denko, 99.95\%, inside diameter $28 \mathrm{~mm}$, depth $25 \mathrm{~mm}$ ): $296 \mathrm{mg}$ of the pyrolyzed wood specimens, $815 \mathrm{mg}$ of Si powder (Mitsuwa Chemicals, 99.999\% purity, 200-mesh) and $791 \mathrm{mg}$ of $\mathrm{Na}$ (Nippon Soda, $99.95 \%$ purity). The crucible was set in a container which is schematically illustrated in Fig. 1. This procedure was carried out in an Ar gas-filled glove box $\left(\mathrm{O}_{2}\right.$ and $\mathrm{H}_{2} \mathrm{O}<$ $1 \mathrm{ppm})$. The container was connected to an Ar gas-feed line and Ar gas (Nippon Sanso, >99.9999\%) was introduced up to about $0.3 \mathrm{MPa}$. The sample specimens were heated at $973 \mathrm{~K}$ for $86.4 \mathrm{ks}$. After heating, the electric power to the heater was shut off to allow cooling of the sample. The BN crucible was taken out of the container in the glove box.

The $\mathrm{Na}$ and $\mathrm{Na}-\mathrm{Si}$ intermetallic compound were removed by reaction with 2-propanol and ethanol in air. The samples were then washed with distilled water using an ultrasonic cleaner and dried at $473 \mathrm{~K}$ in air.

The samples were crushed with an agate pestle and a motar. A scanning electron microscope with a field emission cathode (SEM, Philips ESEM XL30) and acceleration voltage of $15 \mathrm{kV}$ was used for observation of the morphology of the fracture surface. Elemental analysis of the fractured samples was performed with an energy dispersive X-ray analyzer (EDX, EDAX) attached to the SEM. X-ray

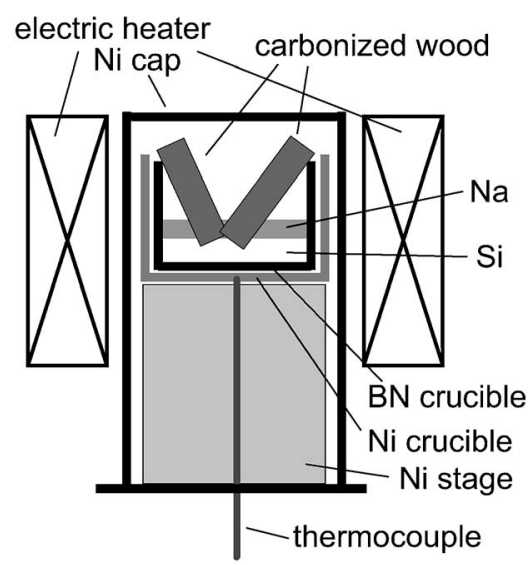

Fig. 1. Experimental apparatus for $\mathrm{SiC}$ wood ceramics. 
diffraction (XRD) patterns were measured on an X-ray diffractometer (RINT2200) using $\mathrm{CuK} \alpha$ radiation produced at $40 \mathrm{kV}$ and $40 \mathrm{~mA}$ with a graphite monochromator to characterize the crystalline phases of the powdered fragments.

\section{Results and discussion}

Photographs of the samples in the crucible before and after heating are shown in Fig. 2. The samples were placed on the $\mathrm{Na}$ metal and heated for $86.4 \mathrm{ks}$. One end of each specimen was in the solidified melt after heating. The surface and cavity wall of the sample above the melt were covered with a thin layer of $\mathrm{Na}$ or $\mathrm{Na}$ and $\mathrm{Na}-\mathrm{Si}$ intermetallic compound. The specimens were detached from the solidified
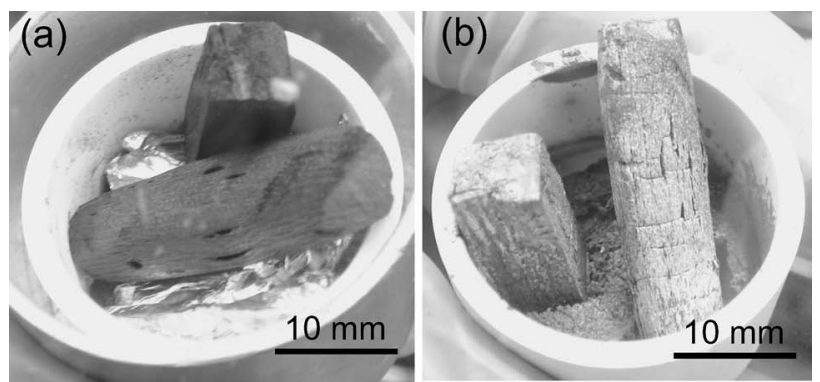

Fig. 2. Photograph of samples before (a) and after heating (b) in a Na-Si melt. melt with a nipper and washed with alcohol first and then with water to remove $\mathrm{Na}$ and the intermetalic compound. The samples maintained the shape of wood after ultrasonic washing.

As shown in Figs. 3 (a) and (b), the carbonized samples were observed by SEM to have the cellular structure of wood. Similar structures of the samples were also observed for the samples after the heating with $\mathrm{Na}$ and $\mathrm{Si}$ at $973 \mathrm{~K}$ (Figs. 3(c) and (d)). The thickness of the wall in the sample made from balsa was thinner than that from Japanese cypress, originating from the difference of the wood anatomies. The chemical composition of these heated samples analyzed by EDX was $\mathrm{C} 45-49$ at $\%, \mathrm{Si} 48-51$ at $\%, \mathrm{O} 2-3$ at $\%$ and $\mathrm{Na}$ ca. 0.7 at $\%$, which was close to the ideal composition of SiC.

Figure 4 shows the $\mathrm{X}$-ray diffraction pattern of the balsa wood sample after heating at $973 \mathrm{~K}$. Diffraction angles and relative intensities of all broad diffraction peaks were consistent with those reported for $\beta$-SiC (cubic, $a=0.436 \mathrm{~nm}$ ). In the previous studies, ${ }^{16), 17)}$ similar broad diffraction patterns of $\beta$-SiC were measured for the powders and porous bulks of the $\mathrm{SiC}$ prepared by using a $\mathrm{Na}$ flux at $1000 \mathrm{~K}$.

With the present method, biomorphic ceramics of crystalline $\beta$-SiC can be produced at $973 \mathrm{~K}$. To the best of our knowledge, this temperature is lowest to date for biomorphic $\mathrm{SiC}$ ceramics. In liquid silicon infiltration processing, samples were heated in a silicon melt at $1823 \mathrm{~K}$ (melting point of Si: $1683 \mathrm{~K}$ ) and then heated up to $1973 \mathrm{~K}$ to eliminate of remnant silicon. ${ }^{4), 7), 8)}$ Other reported

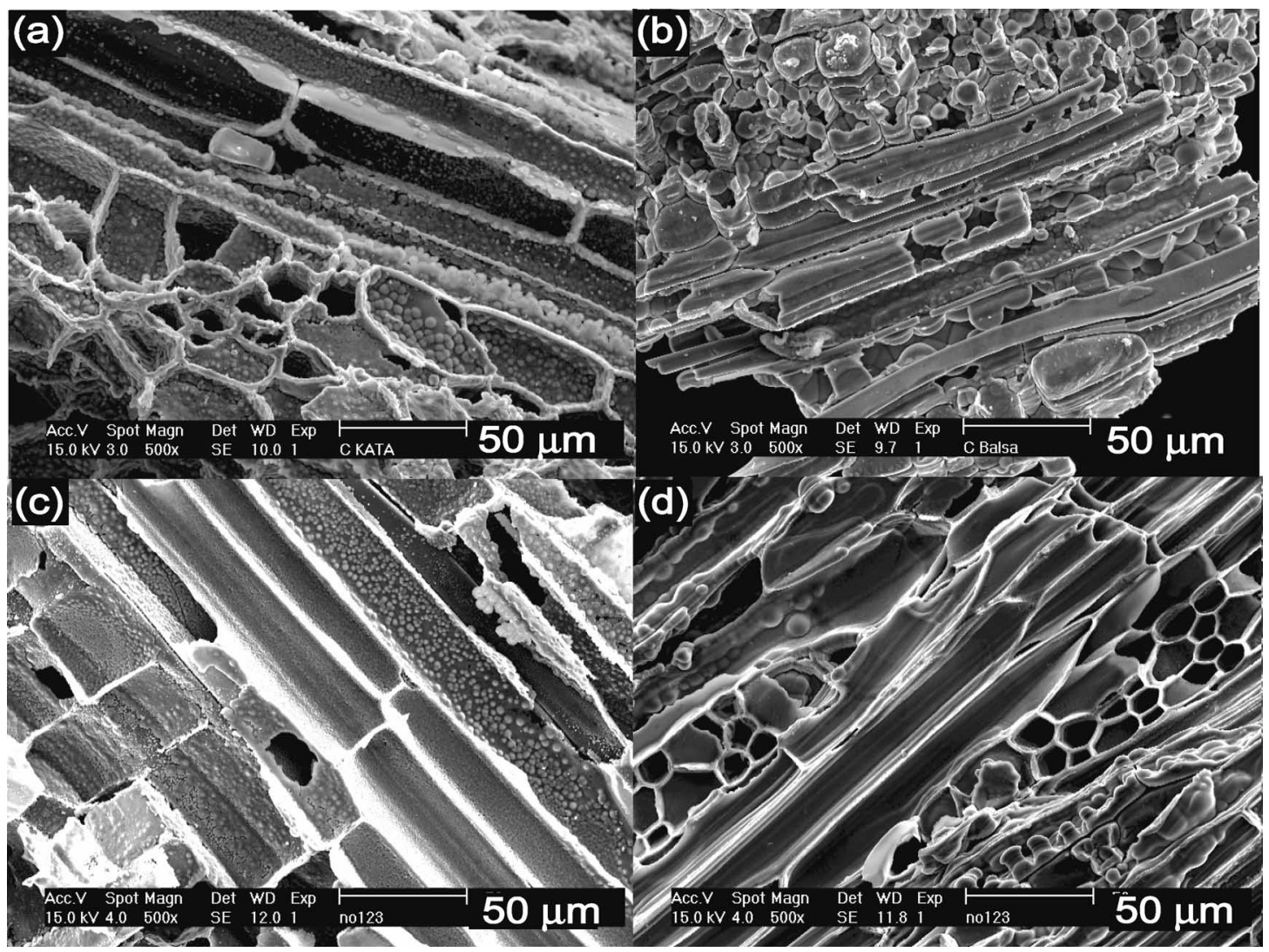

Fig. 3. SEM images of the fracture surfaces of carbonized balsa (a) and Japanese cypress (b), and cellular SiC ceramics converted from carbonized balsa (c) and Japanese cypress (d) at $973 \mathrm{~K}$ for $86.4 \mathrm{ks}$. 


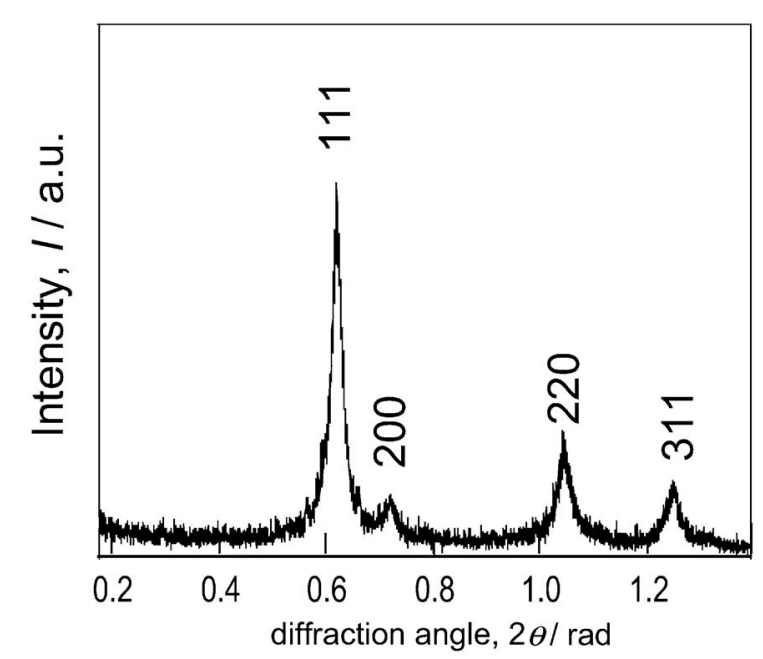

Fig. 4. XRD pattern of the powdered sample prepared with carbonized balsa wood.

methods for the synthesis of the biomorphic SiC ceramics also require temperatures above $1573 \mathrm{~K}$ for the pyrolysis of Si contained vapors ${ }^{9)}$ and precursors and for carbothermal reduction. ${ }^{10)-14)}$ In the previous high-temperature processes, grain growth was observed at the cellular wall. In our low temperature synthesis, the fine structure and texture of the original carbonized wood structure were fairly well maintained (Fig. 3).

No phase diagram has been reported for the Na-Si binary system. However, as discussed in the previous reports, ${ }^{17}$ some amount of $\mathrm{Si}$ is considered to be dissolved in a $\mathrm{Na}$ melt. In the present study, the $\mathrm{Na}$ melt containing $\mathrm{Si}$ probably infiltrated into the samples by capillary force or due to the wettability of the melt to the carbonized wood, and reacted with the carbonized wood to form $\beta$-SiC.

To summarize, biomorphic $\beta$-SiC ceramics were fabricated by heating carbonized wood with $\mathrm{Na}$ and $\mathrm{Si}$ at $973 \mathrm{~K}$ under an Ar atmosphere. Application of this process for the preparation of macro-porous ceramics with synthetic carbon templates would also seem to be possible.

Acknowledgements This study was supported in part by a Science Research Expenses Subsidy from the Ministry of Education, Culture, Sports, Science and Technology, Grant-in-Aid for Exploratory Research, 18655083, 2007.

\section{References}

1) G. Roewer, U. Herzog, K. Trommer, E. Müller and S. Frühauf, Struct. Bond., 101, 59-135 (2002).

2) P. Greil, J. Eur. Ceram. Soc., 21, 105-118 (2001).

3) M. Sing, J. Martinez-Fernandez and A. R. Arellano-Lopez, Curr. Opin. Solid State Mater. Sci., 7, 247-254 (2003).

4) P. Gonzalez, J. Serra, S. Liste, S. Chiussi, B. Leon, M. PerezAmor, J. Martinez-Fernandez, A. R. Alrellano-Lopez and F. M. Varela-Feria, Biomater., 24, 4827-4832 (2003).

5) P. Colombo, Phil. Trans. R. Soc., A 364, 109-124 (2006).

6) A. R. Studart, U. T. Gonzenbach, E. Tervoort and L. J. Gauckler, J. Am. Cerm. Soc., 89, 1771-1789 (2006).

7) P. Greil, T. Lifka and A. Kaindl, J. Eur. Ceram. Soc., 18, 1961-1973 (1998).

8) G. Hou, Z. Jin and J. Qian, Mater. Sci. Eng., A 452-453, 278-283 (2007).

9) E. Vogli, J. Mukerji, C. Hoffmann, R. Kladny, H. Sieber and P. Greil, J. Am. Ceram. Soc., 84, 1236-1240 (2001).

10) T. Ota, M. Takahashi, T. Hibi, M. Ozawa, S. Suzuki, Y. Hikichi and H. Suzuki, J. Am. Ceram. Soc., 78, 3409-3411 (1995).

11) J. Qian, J. Wang and Z. Jin, Mater. Sci. Eng., A 371, 229-235 (2004).

12) J.-M. Qian, J.-P. Wang, G.-J. Qiao and Z.-H. Jin, J. Eur. Ceram. Soc., 24, 3251-3259 (2004).

13) A. Herzog, R. Klingner, U. Vogt and T. Graule, J. Am. Ceram. Soc., 87, 784-793 (2004).

14） J.-M. Qian and Z.-H. Jin, J. Eur. Ceram. Soc., 26, 1311-1316 (2006).

15) K. Vyshnyakova, G. Yushin, L. Pereselentseva and Y. Gogotsi, Int. J. Appl. Ceram. Technol., 3, 485-490 (2006).

16) F. Kawamura, H. Yamane, T. Yamada, S. Yin and T. Sato, $J$. Ceram. Soc. Japan, 115, 74-76 (2007).

17) F. Kawamura, H. Yamane, T. Yamada, S. Yin and T. Sato, $J$. Am. Ceram. Soc., in press. 